\title{
Effects of Combination Therapy with Renin-Angiotensin System Inhibitors and Eicosapentaenoic Acid on IgA Nephropathy
}

\author{
Takahito Moriyama, Chihiro Iwasaki, Kayu Tanaka, Ayami Ochi, Ari Shimizu, \\ Syunji Shiohira, Mitsuyo Itabashi, Takashi Takei, Keiko Uchida, \\ Ken Tsuchiya and Kosaku Nitta
}

\begin{abstract}
Objective The beneficial effects of renin-angiotensin-aldosterone system inhibitors (RASI) and the omega-3 polyunsaturated fatty acid eicosapentaenoic acid (EPA) on $\operatorname{IgA}$ nephropathy (IgAN) have been reported. However, it is unknown whether these agents have any synergistic interactions.

Methods We divided 38 IgAN patients into two groups: an EPA group $(n=18)$ treated with RASI plus EPA and a DILAZEP group $(n=20)$ treated with RASI plus dilazep dihydrochloride. We analyzed the clinical and histological background of each patient, any relevant clinical findings obtained one year after treatment and any factors significantly related to decreases in proteinuria.

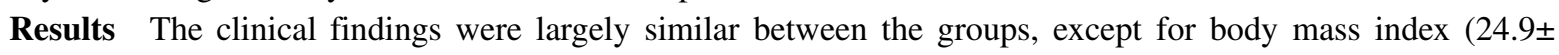
4.5 in the EPA group vs. 21.4 \pm 2.1 in the DILAZEP group, $\mathrm{p}=0.0041$ ) and total cholesterol (median: 206.0 vs. $177.5 \mathrm{mg} / \mathrm{dL}, \mathrm{p}=0.0493$ ). The histological findings, evaluated according to the Oxford classification, were also similar between the groups. At one year after treatment, the EPA group demonstrated a significantly decreased mean blood pressure (from $94.7 \pm 9.0$ to $86.4 \pm 7.2 \mathrm{mmHg}, \mathrm{p}=0.0007$ ) and a significantly decreased median level of proteinuria (from 0.80 to $0.41 \mathrm{~g} / \mathrm{g}$ creatinine, $\mathrm{p}<0.001$ ). In the DILAZEP group, the mean blood pressure significantly decreased (from $95.2 \pm 13.2$ to $88.1 \pm 7.7 \mathrm{mmHg}, \mathrm{p}<0.001$ ) without any significant decrease in the median level of proteinuria (from 0.88 to $0.60 \mathrm{~g} / \mathrm{g}$ creatinine). According to a multivariate logistic analysis, EPA was found to be the only independent factor related to decreases in proteinuria (odds ratio $=5.073,95 \%$ CI: $1.18-26.7, \mathrm{p}=0.0285)$.

Conclusion We conclude that EPA accelerates the effects of RASI and thus decreases the proteinuria observed in patients with IgAN.
\end{abstract}

Key words: IgA nephropathy, renin, angiotensin-aldosterone, inhibitor, omega-3 polyunsaturated fatty acid, eicosapentaenoic acid

(Intern Med 52: 193-199, 2013)

(DOI: 10.2169/internalmedicine.52.8323)

\section{Introduction}

During the four decades since immunoglobulin A nephropathy (IgAN) was first reported, many advances in our understanding of this disorder have been reported (1-6). The renal function and the amount of proteinuria at the time of a renal biopsy and during the follow-up period appear to be related to the IgAN prognosis, as is the severity of the histological findings. Indeed, the most important factor in preventing progression to end-stage renal disease is the degree to which treatment decreases proteinuria (7-10). IgAN is a slowly progressive disease, and its prognosis is difficult to evaluate during the long-term follow-up period. Therefore, 
proteinuria is a good marker for evaluating the effectiveness of therapies in treating IgAN specifically instead of estimating the long-term renal prognosis generally (7-10).

Renin-angiotensin-aldosterone system inhibitors (RASIs) and the omega-3 polyunsaturated fatty acid eicosapentaenoic acid (EPA) have been reported to be effective therapies for IgAN (11-16). RASIs have been found to decrease the amount of proteinuria occurring due to glomerular hypertension and hyperfiltration (11-13). EPA has also been found to reduce proteinuria, in addition to limiting the production and activation of several cytokines, thereby suppressing mediators of the renal function and ameliorating renal deterioration (14-16).

Because of their shared actions and apparently different mechanisms of action, we hypothesized that combination therapy with RASI plus EPA might reduce the amount of urinary protein excretion in patients with $\operatorname{Ig} \mathrm{A}$ nephropathy to a greater degree than RASI alone. In this retrospective cohort analysis, we compared the relative effects of RASI plus EPA and RASI plus the antiplatelet agent dilazep dihydrochloride in reducing the amount of proteinuria after one year of treatment.

\section{Materials and Methods}

Between January 1990 and December 2009, 665 patients were diagnosed with primary IgAN based on the results of renal biopsies at Tokyo Women's Medical University. The patients' ages ranged from 16 to 79 years. The diagnosis of IgAN was made based on light-microscopic findings of mesangial proliferative changes, immunofluorescent detection of mesangial $\mathrm{IgA}$ deposition and electron-microscopic findings of electron-dense deposits in the mesangial area. Patients with systemic diseases such as diabetes mellitus, collagen disorders, abnormal hyper-gammaglobulinemia and chronic liver disease at the time of renal biopsy were excluded from this study. Patients were also excluded if they were not clinically examined for various parameters, such as blood pressure, renal function, total cholesterol, triglycerides, a quantitative analysis of proteinuria and the urinary red blood cell number both before and one year after treatment. We selected all patients treated with either RASI plus EPA combination therapy (EPA group: $n=18$ ) or RASI plus dilazep dihydrochloride combination therapy (DILAZEP group: $\mathrm{n}=20$ ). In the EPA group, 15 patients were given $1,800 \mathrm{mg} /$ day of EPA, two patients received 1,200 $\mathrm{mg} /$ day of EPA and one patient was administered $900 \mathrm{mg} /$ day of EPA. In the DILAZEP group, all patients were given 300 $\mathrm{mg}$ /day of dilazep dihydrochloride. The selection of RASIs was not fixed, and the choice of drug was therefore at the doctor's discretion. The dose of RASI was adjusted to maintain a blood pressure of 130/80 $\mathrm{mmHg}$. In the EPA group, angiotensin-converting enzyme inhibitors (ACEIs) were administered to two patients and angiotensin receptor blockers (ARBs) were given to 17 patients. In the DILAZEP group, 12 patients received ACEIs and eight were given ARBs.
Beta-hydroxy-beta methylglutanyl-coenzyme A reductase inhibitors (statins) were administered to four patients in the EPA group and to zero patients in the DILAZEP group. Data for the following clinical parameters were gathered from every patient before treatment: sex, age, body mass index (BMI), systolic blood pressure (S-BP), diastolic blood pressure (D-BP) and mean blood pressure (M-BP). Furthermore, laboratory data were also gathered, including the levels of serum total protein (TP), serum albumin (Alb), blood urea nitrogen $(\mathrm{BUN})$, serum creatinine $(\mathrm{S}-\mathrm{Cr})$, estimated glomerular filtration rate (eGFR), serum uric acid (UA), serum total cholesterol (T-Cho), high-density lipoproteincholesterol (HDL-C), triglycerides (TGs), serum IgG, serum IgA, serum IgM, CH50, C3, C4, U-Prot and urinary red blood cells (U-RBCs). These clinical and laboratory data can be found in Table 1. The levels of M-BP, e-GFR, UProt, U-RBC, T-Cho and TG were then re-evaluated one year after treatment. Serial changes in the levels of M-BP and U-Prot were also evaluated. This cohort study was conducted in accordance with the Declaration of Helsinki and approved by the Medical Ethics Committee of Tokyo Women's Medical University (\#2606).

\section{Histological findings of the renal biopsy specimens}

All specimens were obtained using percutaneous needle biopsies. The specimens were fixed with $10 \%$ phosphatebuffered formalin ( $\mathrm{pH} 7.2$ ), embedded in paraffin and cut into 4- $\mu \mathrm{m}$-thick sections. These sections were stained with hematoxylin and eosin, periodic acid-Schiff, silver methenamine and Masson trichrome for light microscopic examination. The histological findings including mesangial and endothelial hypercellularity, segmental glomerular sclerosis and tubular atrophy/interstitial fibrosis, which were graded according to the Oxford classification $(17,18)$. Biopsies containing $<8$ glomeruli were excluded from the analysis. All biopsy specimens were also evaluated using an immunofluorescence analysis.

\section{Statistical analysis}

The data are expressed as the mean \pm standard deviation for normally distributed data and as the median with interquartile ranges (IQR) for non-normally distributed data. All results were analyzed using $\mathrm{JMP}^{\circledR} 8.0 .1$ (SAS Institute Inc., Cary, NC, USA) and STATMATE for Windows. Normally and non-normally distributed data were analyzed using unpaired Student's $t$-test and the Mann-Whitney $U$-test, respectively. The $\chi^{2}$ test was used to compare histological grades and sex distribution at the time of renal biopsy between the groups. An analysis of variance (ANOVA) for normally distributed data (M-BP) and the Friedman test for nonnormally distributed data (U-Prot) were used to evaluate serial changes. Paired Student's $t$-test for normally distributed data (M-BP, eGFR and T-Cho) and the Wilcoxon signedrank test for non-normally distributed data (TG, U-Prot and U-RBC) were used to evaluate any changes between values obtained at the time of treatment and one year after treat- 
Table 1. Clinical Findings for Both Groups at the Time of Renal Biopsy

\begin{tabular}{lcccc}
\hline & & EPA & DILAZEP & p value \\
\hline Sex & $($ Male/Female $)$ & $9 / 9$ & $11 / 9$ & NS \\
Age & $($ years $)$ & $38.0 \pm 15.0$ & $38.6 \pm 8.84$ & NS \\
S-BP & $(\mathrm{mmHg})$ & $126.9 \pm 11.6$ & $128.8 \pm 16.4$ & $\mathrm{NS}$ \\
D-BP & $(\mathrm{mmHg})$ & $78.6 \pm 9.8$ & $78.5 \pm 14.2$ & $\mathrm{NS}$ \\
M-BP & $(\mathrm{mmHg})$ & $94.7 \pm 9.0$ & $95.2 \pm 13.2$ & $\mathrm{NS}$ \\
BMI & $\left(\mathrm{kg} / \mathrm{m}^{2}\right)$ & $24.9 \pm 4.5$ & $21.4 \pm 2.1$ & 0.0041 \\
& & & & \\
TP & $(\mathrm{g} / \mathrm{dL})$ & $6.84 \pm 0.61$ & $6.73 \pm 0.73$ & $\mathrm{NS}$ \\
Alb & $(\mathrm{g} / \mathrm{dL})$ & $4.08 \pm 0.47$ & $3.99 \pm 0.49$ & $\mathrm{NS}$ \\
BUN & $(\mathrm{mg} / \mathrm{dL})$ & $16.2 \pm 4.63$ & $17.4 \pm 5.85$ & $\mathrm{NS}$ \\
S-Cre & $(\mathrm{mg} / \mathrm{dL})$ & $0.92(0.81-1.10)$ & $0.88(0.71-1.08)$ & $\mathrm{NS}$ \\
e-GFR & $(\mathrm{mL} / \mathrm{min})$ & $59.7 \pm 16.9$ & $65.0 \pm 22.6$ & $\mathrm{NS}$ \\
UA & $(\mathrm{mg} / \mathrm{dL})$ & $6.29 \pm 1.42$ & $6.05 \pm 1.67$ & $\mathrm{NS}$ \\
T-Cho & $(\mathrm{mg} / \mathrm{dL})$ & $206(178-237)$ & $177(153-219)$ & 0.0493 \\
HDL-C & $(\mathrm{mg} / \mathrm{dL})$ & $51.2 \pm 14.2$ & $52.1 \pm 12.7$ & $\mathrm{NS}$ \\
TG & $(\mathrm{mg} / \mathrm{dL})$ & $139.7 \pm 58.1$ & $122.7 \pm 59.0$ & $\mathrm{NS}$ \\
& & & & \\
IgG & $(\mathrm{mg} / \mathrm{dL})$ & $1,125 \pm 196$ & $1,138 \pm 257$ & $\mathrm{NS}$ \\
IgA & $(\mathrm{mg} / \mathrm{dL})$ & $303(254-391)$ & $327(276-471)$ & $\mathrm{NS}$ \\
IgM & $(\mathrm{mg} / \mathrm{dL})$ & $69.5(53.5-94.0)$ & $114.5(83.3-153.5)$ & $\mathrm{NS}$ \\
CH50 & $(\mathrm{mg} / \mathrm{dL})$ & $41.7 \pm 7.0$ & $41.3 \pm 7.4$ & $\mathrm{NS}$ \\
C3 & $(\mathrm{mg} / \mathrm{dL})$ & $100.8 \pm 17.2$ & $90.2 \pm 30.3$ & $\mathrm{NS}$ \\
C4 & $(\mathrm{mg} / \mathrm{dL})$ & $24.2(21.7-27.4)$ & $24.4(20.9-33.1)$ & $\mathrm{NS}$ \\
& & & & \\
U-Prot & $(\mathrm{g} / \mathrm{g} \cdot \mathrm{Cre})$ & $0.80(0.29-1.28)$ & $0.88(0.43-1.20)$ & $\mathrm{NS}$ \\
U-RBC & $(\mathrm{counts} / \mathrm{HF})$ & $10.0(1.0-30.0)$ & $10.0(2.0-30.0)$ & $\mathrm{NS}$ \\
\hline & & & &
\end{tabular}

Table 2. Oxford Classification of the Histological Grade of IgAN in Each Group

\begin{tabular}{cccc}
\hline & EPA group & DILAZEP group & p value \\
\hline Mesangial hypercellularity (M0/M1) & $13 / 4$ & $10 / 7$ & $\mathrm{NS}$ \\
Endocapillary hypercellularity (E0/E1) & $10 / 7$ & $9 / 8$ & $\mathrm{NS}$ \\
Segmental glomerulosclerosis (S0/S1) & $2 / 15$ & $4 / 13$ & $\mathrm{NS}$ \\
Tubular atrophy/Interstitial fibrosis (T0/T1/T2) & $15 / 1 / 1$ & $10 / 3 / 4$ & $\mathrm{NS}$ \\
Not classified & 1 & 3 & \\
\hline
\end{tabular}

ment in each group. A multivariate-adjusted logistic analysis was used to evaluate factors related to decreasing levels of U-Prot. Differences with $\mathrm{p}$ values $<0.05$ were considered to be statistically significant in all analyses.

\section{Results}

\section{Comparison of clinical findings obtained at the time of renal biopsy in each group}

Table 1 shows the clinical findings obtained at the time of renal biopsy in each group. Sex, age, S-BP, D-BP and M-BP were not significantly different between the two groups. BMI was significantly higher in the EPA group than in the DILAZEP group $\left(24.9 \pm 4.5 \mathrm{~kg} / \mathrm{m}^{2}\right.$ vs. $21.4 \pm 2.1 \mathrm{~kg} / \mathrm{m}^{2}, \mathrm{p}=$
0.0041). Regarding the laboratory data, there were no significant differences between the two groups in any parameter, with the exception that the median T-Cho level was significantly higher in the EPA group than in the DILAZEP group [206.0 (178.5-237.0) $\mathrm{mg} / \mathrm{dL}$ vs. 177.5 (153.8-219.0) $\mathrm{mg} / \mathrm{dL}, \mathrm{p}=0.0493$ ]. Importantly, the levels of U-Prot and URBC were not significantly different between the two groups.

\section{Comparison of histological findings between the EPA and DILAZEP groups}

Table 2 shows the results of histological evaluations of samples according to the Oxford classification. After performing an analysis using the $\chi^{2}$ test, we found no significant differences in histological grade between the EPA and 


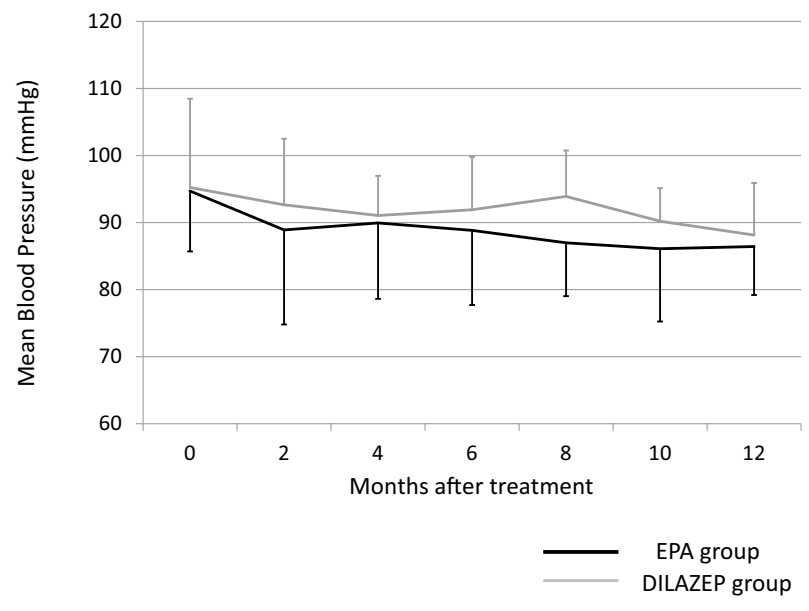

Figure 1. Serial changes in the mean blood pressure in the EPA and DILAZEP groups from before treatment to 12 months after treatment. The mean blood pressure $(\mathrm{mmHg})$ in the EPA group was $94.7 \pm 9.0$ before treatment, $88.9 \pm 14.1$ at two months, $89.9 \pm 11.3$ at four months, $88.8 \pm 11.1$ at six months, 87.0 \pm 8.0 at eight months, $86.1 \pm 10.9$ at 10 months and 86.4 \pm 7.2 at 12 months after treatment. There was a significant difference, as assessed with ANOVA, from 0 to 12 months after treatment $(\mathbf{p}<0.001)$. The mean blood pressure in the DILAZEP group was $95.2 \pm 13.2$ before treatment, $92.6 \pm 9.9$ at two months, 91.1 \pm 5.9 at four months, $91.9 \pm 7.9$ at six months, 93.9 \pm 6.9 at eight months, $90.2 \pm 4.9$ at 10 months and 91.6 \pm 8.0 at 12 months after treatment. There was a significant difference, as assessed with ANOVA, from 0 to 12 months after treatment $(\mathbf{p}<0.001)$.

DILAZEP groups. Four patients were excluded from the histological evaluation for having less than eight glomeruli.

\section{Comparison of clinical findings in each group be- fore and after treatment}

The time course changes in the levels of M-BP and UProt are shown in Figs. 1, 2. The values of each clinical parameter measured before and one year after treatment are shown in Table 3. In both groups, the changes in M-BP assessed with ANOVA were significantly different during the follow-up period (EPA group: $\mathrm{p}<0.001$, DILAZEP group: $\mathrm{p}<$ 0.001). Moreover, in the EPA group, M-BP was significantly decreased at one year after treatment (from 94.7 \pm 9.0 to $86.4 \pm 7.2 \mathrm{mmHg}, \mathrm{p}=0.0007$ ), and in the DILAZEP group, M-BP was also significantly decreased at one year after treatment (from $95.2 \pm 13.2$ to $88.1 \pm 7.7 \mathrm{mmHg}, \mathrm{p}=0.0142$ ). The values of eGFR, T-Cho and TG did not differ significantly before and after treatment. The changes in the levels of U-Prot assessed with the Friedman test were not significantly different between the two groups. However, in a simple comparison of data obtained before and one year after treatment, the median level of U-Prot was found to have significantly decreased in the EPA group [from $0.80(0.29$ 1.28) g/g Cr to 0.41 (0.18-0.77) g/g Cr, p<0.001]. However, this decrease was not apparent in the DILAZEP group, despite a trend towards decreasing U-Prot values in that group

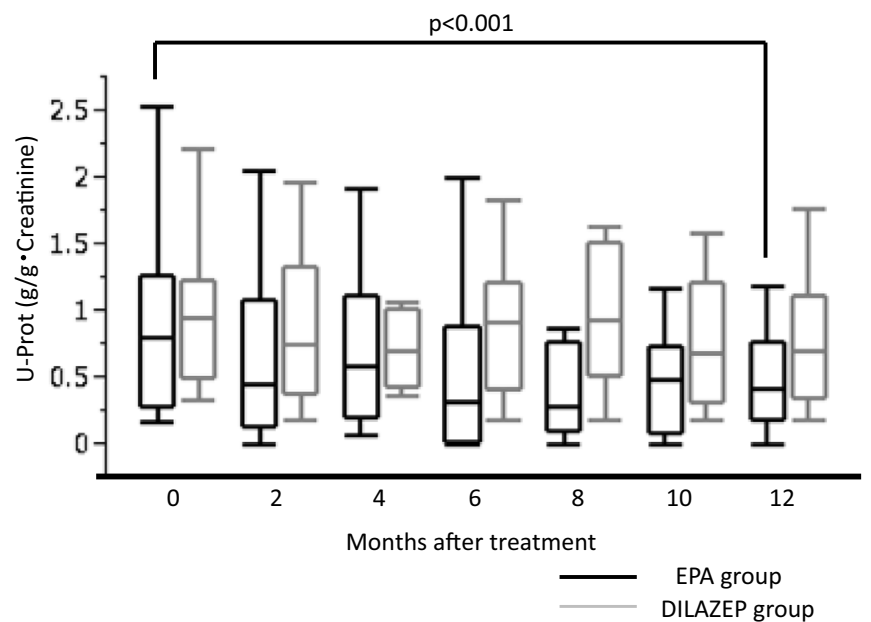

Figure 2. Serial changes in the levels of U-Prot in the EPA and DILAZEP groups from before treatment to 12 months after treatment. The median U-Prot (g/gCre) level in the EPA group was $0.80(0.29-1.28)$ before treatment, $0.40(0.14-1.06)$ at two months, $0.58(0.20-1.11)$ at four months, $0.31(0.03-0.88)$ at six months, $0.28(0.10-0.77)$ at eight months, $0.49(0.08-0.73)$ at 10 months and $0.41(0.18-0.77)$ at 12 months after treatment. There were no significant differences according to the Friedman test from 0 to 12 months after treatment. However, there was a significant difference between the values obtained before treatment and at 12 months after treatment $(p<0.001)$. The median level of U-Prot (g/gCre) in the DILAZEP group was $0.88(0.43-1.20)$ before treatment, $0.67(0.24-1.34)$ at two months, $0.61(0.24-0.98)$ at four months, $0.86(0.27-1.22)$ at six months, $0.87(0.40-1.55)$ at eight months, $0.59(0.16-1.22)$ at 10 months and $0.60(0.21-1.11)$ at 12 months after treatment. There were no significant differences, according to the Friedman test, from 0 to 12 months after treatment.

[from $0.88(0.43-1.20) \mathrm{g} / \mathrm{g} \mathrm{Cr}$ to $0.60(0.21-1.10) \mathrm{g} / \mathrm{g} \mathrm{Cr}$ ]. The U-RBC values did not differ significantly before and after treatment in either group.

\section{Multivariate analysis of factors related to decreasing levels of U-Prot}

We used the clinical and histological findings to perform a multivariate adjusted logistic analysis to define factors linked to decreases in the U-Prot values. Among our clinical findings, EPA therapy was the only independent factor found to induce a $50 \%$ decrease in the levels of U-Prot [odds ratio (HR): 5.073, 95\% CI: 1.18-26.7, p=0.0285] (Table 4). None of the Oxford histological parameters were linked to decreases in the levels of U-Prot.

\section{Discussion}

In this study, we have shown that a 'RASI plus EPA' combination therapy causes significantly larger decreases in the levels of proteinuria than a 'RASI plus dilazep dihydrochloride' combination therapy. We have also shown, using a multivariate logistic analysis, that EPA was the only inde- 
Table 3. Comparison of Clinical Findings at the Time of Renal Biopsy and at 1 Year after Treatment

\begin{tabular}{|c|c|c|c|c|}
\hline & & Baseline & 1 year after treatment & $p$ value \\
\hline \multicolumn{5}{|c|}{ EPA group } \\
\hline M-BP & $(\mathrm{mmHg})$ & $94.7 \pm 9.0$ & $86.4 \pm 7.2$ & 0.0007 \\
\hline e-GFR & $(\mathrm{mL} / \mathrm{min})$ & $59.7 \pm 16.9$ & $60.3 \pm 23.1$ & NS \\
\hline T-Cho & $(\mathrm{mg} / \mathrm{dL})$ & $206.0(178.5-237.0)$ & $190.0(178.0-222.5)$ & NS \\
\hline TG & $(\mathrm{mg} / \mathrm{dL})$ & $139.7 \pm 58.1$ & $129.4 \pm 69.8$ & NS \\
\hline U-Prot & $(g / g \cdot C r e)$ & $0.80(0.29-1.28)$ & $0.41(0.18-0.77)$ & $<0.001$ \\
\hline U-RBC & (counts/HF) & $10.0(1.0-30.0)$ & $5.0(1.0-20.0)$ & NS \\
\hline \multicolumn{5}{|c|}{ DILAZEP group } \\
\hline M-BP & $(\mathrm{mmHg})$ & $95.2 \pm 13.2$ & $88.1 \pm 7.7$ & 0.0142 \\
\hline e-GFR & $(\mathrm{mL} / \mathrm{min})$ & $65.0 \pm 22.6$ & $66.0 \pm 28.1$ & NS \\
\hline T-Cho & $(\mathrm{mg} / \mathrm{dL})$ & $177.5(153.8-219.0)$ & $168.0(151.5-204.8)$ & NS \\
\hline TG & $(\mathrm{mg} / \mathrm{dL})$ & $117.6 \pm 59.8$ & $141.4 \pm 88.4$ & NS \\
\hline U-Prot & $(g / g \cdot C r e)$ & $0.88(0.43-1.20)$ & $0.60(0.21-1.10)$ & NS \\
\hline U-RBC & (counts/HF) & $10.0(2.0-30.0)$ & $10.0(4.0-14.0)$ & NS \\
\hline
\end{tabular}

Table 4. Odds Ratio of Achieving a 50\% Decrease in U-Prot in Multivariate Logistic Regression

\begin{tabular}{lccc}
\hline & Odds ratio & 95\% Cl & p value \\
\hline Clinical Findings & & & \\
\hline M-BP (per 10 mmHg decrease) & 1.012 & $0.41-2.52$ & 0.9781 \\
U-Prot (per 0.5g/g Cre decrease) & 0.837 & $0.47-1.33$ & 0.4619 \\
U-RBC (per 25/HPF decrease) & 0.732 & $0.35-1.41$ & 0.3430 \\
eGFR (per 10 ml/min increase) & 0.763 & $0.46-1.18$ & 0.2312 \\
With EPA therapy (vs. without EPA) & 5.073 & $1.18-26.7$ & 0.0285 \\
\hline Histological findings (Oxford classification) & & \\
\hline Mesangial hypercellularity & 5.17 & $0.78-48.1$ & 0.0896 \\
Endocapillary hypercellularity & 0.29 & $0.04-1.47$ & 0.1411 \\
Segmental glomerulosclerosis & 2.19 & $0.30-23.7$ & 0.4517 \\
Tubular atrophy/lnterstitial fibrosis & 0.68 & $0.19-2.12$ & 0.5133 \\
\hline
\end{tabular}

pendent factor that could be statistically related to decreases in proteinuria. These results indicate that EPA synergistically potentiates or accelerates the effects of RASIs in decreasing proteinuria. Several previous reports from various countries have facilitated a full understanding of the renoprotective effects of RASIs (11-13). Results from our laboratory have also demonstrated the beneficial effects of these medications, especially in patients with advanced IgAN with an impaired renal function (19-21), a condition for which fish oil therapies, including the omega-3 polyunsaturated fatty acids (PUFA) eicosapentaenoic acid and docosahexaenoic acid (DHA), are also beneficial, as reported by several groups (22-25). In an elegant series of studies, Donadio and colleagues reported the short- and long-term beneficial effects of fish oil on IgAN using a randomized controlled trial. They found that a two-year fish oil therapy produced a significant decrease in the number of patients experiencing $50 \%$ elevations in the creatinine levels from baseline in comparison with a placebo group $(6 \%$ vs. $33 \%, \mathrm{p}=$ 0.002) (22). Furthermore, this treatment also reduced the number of cases that reached end-stage renal disease $(15 \%$ vs. $44 \%, \mathrm{p}=0.009$ ), although the therapy did not significantly affect the levels of proteinuria (23). Interestingly, the effectiveness was not dose-dependent (24). However, both a meta-analysis (25) and a review (26) of this therapy, both of which incorporated the work of Donadio and colleagues, concluded that the effectiveness remained controversial. However, the mechanisms by which $\omega-3$ PUFAs exert their renoprotective effects have been analyzed and confirmed in experimental models of kidney disease. In glomerular endothelial cells, oxidized PUFAs modulate pro-inflammatory

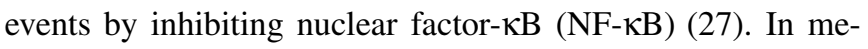
sangial cells, EPA inhibits platelet-derived growth factorstimulated mesangial cell mitogenesis and the cyclin D1 expression via transforming growth factor- $\beta$ (28). EPA and DHA also inhibit tumor necrosis factor- $\alpha$ (TNF- $\alpha$ )stimulated transcription of the monocyte chemo-attractant protein 1 (MCP-1) gene through interaction with signaling pathways involving extracellular signal-regulated kinase (ERK) and NF-KB (29). In vivo, fish oil treatment reduces 
proteinuria and mesangial activation and proliferation in anti-Thy 1.1 rats (30). Furthermore, in a mycotoxin-induced IgAN mouse model, EPA and DHA were found to suppress increases in the expression of serum $\operatorname{IgA}, \operatorname{IgA}$ immune complex and interleukin-6 $(31,32)$ in addition to mitogenactivated protein kinase activation and the cyclooxygenase expression (32). We therefore hypothesized that the antiinflammatory effects of EPA might allow it to synergize with RASI to produce improved renoprotective effects by decreasing the levels of proteinuria experienced in patients with IgAN. It has been reported that a 'RASI plus PUFA' combination therapy decreases proteinuria in IgAN patients (33). Six months of additional treatment with PUFAs in 15 IgAN patients who had already been treated with RASIs produced a $72.9 \%$ decrease (compared to baseline) in the levels of proteinuria (from $1.31 \pm 1.20 \mathrm{~g} /$ day to $0.37 \pm 0.52$ $\mathrm{g} /$ day), a statistically significant difference $(\mathrm{p}<0.001)$. In contrast, administration of RASI alone over the same sixmonth period did not change the levels of proteinuria. Furthermore, erythrocyturia was significantly decreased in the PUFA group ( $\mathrm{p}=0.031$ ), but not in the control group (33). These results support our hypothesis that the 'RASI plus EPA' combination therapy decreases IgAN-associated proteinuria more than the 'RASI plus dilazep dihydrochloride' combination.

However, our study has some limitations. First, the study design is a retrospective observational study and the sample size was very small. Indeed, there were some significant and non-significant differences between the two groups. For example, the number of advanced cases involving $\mathrm{T} 2$ and $\mathrm{T} 3$ in the Oxford analysis tended to be higher in the DILAZEP group, and the ACEI/ARB ratio was also higher in the DILAZEP group. In our previous reports, we demonstrated the long-term beneficial effects of RASIs on the prevention of end-stage renal disease; however, we could not show any effects causing significant decreases in the levels of U-Prot in the advanced $\operatorname{IgAN}$ cases $(20,21)$, and the decreases in the levels of U-Prot caused by ARBs were greater than those caused by ACEIs in these cases (19). In addition, we could not deny that these differences between the groups accounted for the lack of significant decreases in the levels of U-Prot in the DILAZEP group, although the ability of RASIs to decrease the levels of U-Prot is widely recognized. Large, prospective, randomized controlled studies should be undertaken to preclude selection bias. Second, the median baseline value of proteinuria was less than $1 \mathrm{~g} / \mathrm{g} \mathrm{Cr}$. This result indicates that the 'RASI plus EPA' combination therapy is effective for treating mild-to-moderate proteinuria; however, these conclusions cannot be extended to more severe cases of proteinuria without further studies of patients with higher baseline U-Prot values. The difficulty presented in conducting such studies is that almost all patients experiencing severe proteinuria are already being treated with steroids, making it impossible to accurately evaluate the effects of 'RASI plus EPA' combination therapy in these patients. Finally, we chose EPA alone as our representative PUFA, whereas previous reports have used Omacor, a combination drug containing both EPA and DHA (22-24, 34). Our justification for choosing EPA is that DHA is not available commercially in Japan and we were thus unable to show the effects of DHA relative to EPA. However, Donadio and colleagues have shown that the effects of PUFAs are independent of the dosage (24), the plasma $\omega$-3 PUFA levels, the EPA/arachidonic acid ratios and the Omacor dosage per kilogram of body weight (34). While we have emphasized the importance of EPA in this study, we must acknowledge that DHA remains a highly important factor in the treatment of proteinuria.

In conclusion, we herein demonstrated a synergistic effect of 'RASI plus EPA' combination therapy in decreasing IgAN-associated proteinuria. However, given the small sample size, the effectiveness of EPA will continue to remain controversial until irrefutable evidence from a large randomized controlled trial is acquired to confirm our results.

The authors state that they have no Conflict of Interest (COI).

\section{References}

1. Strippoli GFM, Manno C, Schena F. An "evidence-based" survey of therapeutic options for IgA nephropathy: Assessment and criticism. Am J Kidney Dis 41: 1129-1139, 2003.

2. Cheng J, Zhang X, Zhang W, He Q, Tao X, Chen J. Efficacy and safety of glucocorticoids therapy for IgA nephropathy: A metaanalysis of randomized controlled trials. Am J Nephrol 30: 315322, 2009.

3. Zhou YH, Tang LG, Guo SL, et al. Steroids in the treatment of $\operatorname{Ig}$ A nephropathy to the improvement of renal survival: A systematic review and meta-analysis. PLoS one 6: e18788, 2011.

4. Floege J, Eitner F. Current therapy for IgA nephropathy. J Am Soc Nephrol 22: 1785-1794, 2011.

5. Barratt J, Feehally J. Treatment of IgA nephropathy. Kidney Int 69: 1934-1938, 2006.

6. Ballardie FW. Quantitative appraisal of treatment options for IgA nephropathy. J An Soc Nephrol 18: 2806-2809, 2007.

7. Reich HN, Troyanov S, Scholey JW, Cattran DC; for the Tront glomerulonephritis registry. Remission of proteinuria improves prognosis in IgA nephropathy. J Am Soc Nephrol 18: 3177-3183, 2007.

8. Dobaldio JV, Bergstralh EJ, Grande JP, Rademeher DM. Proteinuria patterns and their association with subsequent end-stage renal disease in IgA nephropathy. Nephrol Dial Transplant 17: 11971203, 2002.

9. Hwang HS, Kim BS, Shin YS, et al. Predictors for progression in immunoglobulin A nephropathy with significant proteinuria. Nephrology 15: 236-241, 2010.

10. Okonogi H, Utsunomiya $\mathrm{Y}$, Miyazaki $\mathrm{Y}$, et al. A predictive clinical grading system for immunoglobulin A nephropathy by combining proteinuria and estimated glomerular filtration rate. Nephron Clin Pract 118: c292-c300, 2011.

11. Dillon JJ. Angiotensin-converting enzyme inhibitors and angiotensin receptor blockers for IgA nephropathy. Semin Nephrol 24: 218-224, 2004.

12. Cheng J, Zhang W, Zhang XH, He Q, Tao XJ, Chen JH. ACEI/ ARB therapy for IgA nephropathy: a meta-analysis of randomized controlled trials. Int J Clin Pract 63: 880-888, 2009.

13. Coppo R, Amore A, Peruzzi L, Mancuso D, Camilla R. Angiotensin antagonists and fish oil for treating $\operatorname{IgA}$ nephropathy. 
Contrib Nephrol 157: 27-36, 2007.

14. Pestka JJ. N-3 polyunsaturated fatty acids and autoimmunomediated glomerulonephritis. Prostaglandins Leukot Essent Fatty Acids 82: 251-258, 2010.

15. Donaldio JV. Use of fish oil to treat patients with immunoglobulin A nephropathy. Am J Clin Nutr 71: 373S-375S, 2000.

16. Grande JP, Donaldio JV. Dietary fish oil supplementation in IgA nephropathy: A therapy in search of a mechanism? Neutrition 14: 240-241, 1998.

17. A working group of the international $\operatorname{IgA}$ nephropathy network and the renal pathology society. The Oxford classification of IgA nephropathy: rationale, clinicopathological correlations, and classification. Kidney Int 76: 534-545, 2009.

18. A working group of the international $\operatorname{IgA}$ nephropathy network and the renal pathology society. The oxford classification of IgA nephropathy: pathology definitions, correlations, and reproducibility. Kidney Int 76: 546-556, 2009.

19. Moriyama T, Amamiya N, Ochi A, et al. Long-term beneficial effects of ACEI and ARB therapy for patients with advanced $\operatorname{IgA}$ nephropathy and impaired renal function. Clin Exp Nephrol 15: 700-707, 2011.

20. Moriyama T, Amemiya N, Ochi A, et al. Comparison of steroids and angiotensin receptor blockers for patients with advanced IgA nephropathy and impaired renal function. Am J Nephrol 34: 233240, 2011.

21. Moriyama T, Nakayama K, Ochi A, et al. Comparison of inhibitors of renin-angiotensin-aldosterone system (RAS) and combination therapy of steroids plus RAS inhibitors for patients with advanced IgA nephropathy and impaired renal function. Clin Exp Nephrol 16: 231-237, 2012.

22. Donadio JV Jr, Bergstralh EJ, Offord KP, Spencer DC, Holley KE; for The Mayo Nephrology Collaborative group. A controlled trial of fish oil in IgA nephropathy. N Engl J Med 331: 11941199, 1994

23. Donadio JV Jr, Grande JP, Bergstralh EJ, Dart RA, Larson TS, Spencer DC; for The Mayo Nephrology Collaborative group. The long-term Outcome of Patients with IgA nephropathy treated with fish oil in a controlled trial. J Am Soc Nephrol 10: 1772-1777, 1999.
24. Donadio JV Jr, Larson TS, Bergstralh EJ, Grande JP; for The Mayo Nephrology Collaborative group. A randomized trial of high-dose compared with low-dose omega-3 fatty acids in severe IgA nephropathy. J Am Soc Nephrol 12: 791-799, 2001.

25. Dillon JJ. Fish oil therapy for IgA nephropathy: Efficacy and interstudy variability. J Am Soc Nephrol 9: 1739-1744, 1997.

26. Fassett RG, Gobe GC, Peake JM, Coombes JS. Omega-3 polyunsaturated fatty acids in the treatment of kidney disease. Am J Kidney Dis 56: 728-742, 2010.

27. Chaudhary A, Mishra A, Sethi S. Oxidized $\omega-3$ fatty acids inhibit pro-inflammatory responses in glomerular endothelial cells. Nephron Experiment 97: e136-e145, 2004.

28. Hida M, Fujita H, Ishikawa K, Omori S, Hoshiya M, Awazu M. Eicosapentaenoic acid inhibits PDGF-induced mitogenesis and cyclin D1 expression via TGF- $\beta$ in mesangial cells. J Cell Phisiol 196: 293-300, 2003.

29. Diaz Encarnacion MM, Warner GM, Cheng J, Gray CF, Nath KA, Grande JP. n-3 fatty acids block TNF- $\alpha$-stimulated MCP- 1 expression in rat mesangial cells. Am J Physiol Renal Physiol 300: F1142-F1151, 2011.

30. Grande JP, Walker HJ, Holub BJ, et al. Suppressive effects of fish oil on mesangial cell proliferation in vitro and in vivo. Kidney Int 57: 1027-1040, 2000.

31. Shi Y, Pestka JJ. Attemuation of mycotoxin- induced IgA nephropathy by eicosapentaenoic acid in the mouse: dose response and relation to IL-6 expression. J Nutr Biochem 17: 697-706, 2006.

32. Jia Q, Zhou HR, Bennink M, Pestka JJ. Docosahexaenoic acid attenuates mycotoxin-induced immunoglobulin A nephropathy, interleukin- 6 transcription, and mitogen-activated protein kinase phosphorylation in mice. J Nutr 134: 3343-3349, 2004.

33. Ferraro PM, Ferraccioli GF, Gambaro G, Fulignati P, Costanzi S. Combined treatment with renin-angiotensin system blockers and polyunsaturated fatty acids in proteinuric IgA nephropathy: a randomized controlled trial. Nephrol Dial Transplant 24: 156-160, 2009.

34. Donadio JV Jr, Bergstralh EJ, Bibus DM, Grande JP. Is body size a biomarker for optimizing dosing of omega-3 polyunsaturated fatty acids in the treatment of patients with IgA nephropathy? Clin J Am Soc Nephrol 1: 933-939, 2006.

(C) 2013 The Japanese Society of Internal Medicine http://www.naika.or.jp/imonline/index.html 